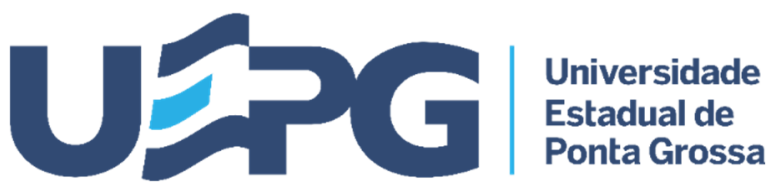

Revista Teias do Conhecimento

Ano 1, Número 1, 2021

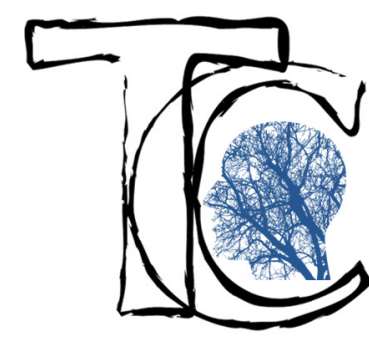

ISSN 2763-6739
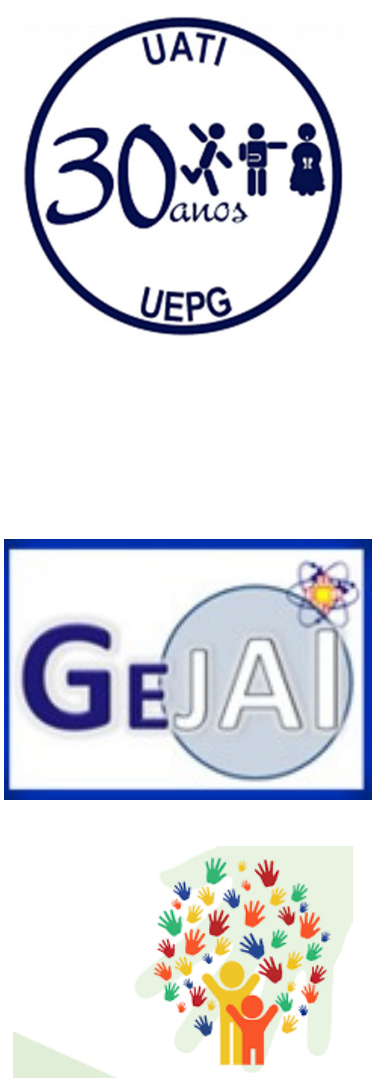

MESTRADO

EM EDUCAÇĀO INCLUSIVA

\title{
ENVELHECIMENTO COMO TEMA TRANSVERSAL NA EDUCAÇÃO BÁSICA
}

\author{
http://doi.org/10.5212/RevTeiasConhecimento.v111.20210030

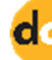 \\ Mônica de Ávila Todaro*
}

https://orcid.org/0000-0001-7777-925X

http://lattes.cnpq.br/1425333434856014

Meire Cachioni*

https://orcid.org/0000-0001-5220-410X

http://lattes.cnpq.br/0974903520016451

RESUMO: Esse artigo tem o objetivo de apresentar e defender a importância do envelhecimento como tema transversal na Educação Básica. Nas áreas da Educação e da Gerontologia, a temática em questão se refere à resposta aos desafios éticos que se apresentam na sociedade brasileira contemporânea. As questões que mobilizam a reflexão, são: Quais as concepções da expressão tema transversal? O envelhecimento vem sendo apresentado como tema transversal na legislação que se refere à Educação Básica? O quadro teórico traz as ideias de Paulo Freire, Busquets e outros pesquisadores contemporâneos. Os resultados da busca que empreendemos nos fizeram compreender que o envelhecimento como tema transversal está presente na legislação que se refere à Educação Básica. Porém, faz-se necessária a luta pela efetivação dos direitos garantidos em leis, para que a inserção do tema nas escolas seja efetiva e coerente com as bases legais.

PALAVRAS-CHAVE: Envelhecimento. Tema transversal. Educação básica.

* Pós-doutora pela Universidade de São Paulo (USP) e Professora do Programa de Pós-Graduação em Educação da Universidade Federal São José del-Rei (UFSJ), mavilatodaro@ufsj.edu.br

* Livre-docente pela Universidade de São Paulo (USP) e Professora do Programa de Pós-Graduação em Educação da Universidade de São Paulo (USP), meirec@usp.br 


\title{
AGING AS A CROSS-CUTTING THEME IN BASIC EDUCATION
}

\begin{abstract}
This article aims to present and defend the importance of aging as a cross-cutting theme in Basic Education. In the areas of Education and Gerontology, the theme in question refers to the response to the ethical challenges that present themselves in contemporary Brazilian society. The questions that mobilize the reflection are: What are the conceptions of the expression transversal theme? Has aging been presented as a cross-cutting theme in the legislation that refers to Basic Education? The theoretical framework brings the ideas of Paulo Freire, Busquets and other contemporary researchers. The results of the search we undertook made us understand that aging as a cross-cutting theme is present in the legislation that refers to Basic Education. However, it is necessary to fight for the realization of rights guaranteed by laws, so that the inclusion of the theme in schools is effective and coherent with the legal bases.
\end{abstract}

KEYWORDS: Aging. Cross theme. Basic education.

\section{EL ENVEJECIMIENTO COMO TEMA TRANSVERSAL EN LA EDUCACIÓN BÁSICA}

RESUMEN: Este artículo tiene como objetivo presentar y defender la importancia del envejecimiento como tema transversal en la Educación Básica. En las áreas de Educación y Gerontología, el tema en cuestión se refiere a la respuesta a los desafíos éticos que se presentan en la sociedad brasileña contemporánea. Las preguntas que movilizan la reflexión son: ¿Cuáles son las concepciones de la expresión tema transversal? ¿Se ha presentado el envejecimiento como un tema transversal en la legislación que se refiere a la Educación Básica? El marco teórico trae las ideas de Paulo Freire, Busquets y otros investigadores contemporáneos. Los resultados de la búsqueda que realizamos nos hicieron comprender que el envejecimiento como tema transversal está presente en la legislación que se refiere a la Educación Básica. Sin embargo, es necesario luchar por la realización de los derechos garantizados por las leyes, para que la inclusión del tema en las escuelas sea efectiva y coherente con las bases legales.

PALABRAS CLAVE: Envejecimiento. Tema cruzado. Educación básica. 


\section{INTRODUÇÃO}

Nesse artigo, temos como objetivo apresentar e defender a importância do envelhecimento como tema transversal na Educação Básica. Para isso, buscamos identificar os termos idosos, velhice e envelhecimento na legislação brasileira. Nas áreas da Educação e da Gerontologia, na perspectiva de uma educação para o envelhecimento, a temática do presente estudo se justifica mediante à resposta aos desafios éticos que se apresentam na sociedade brasileira contemporânea.

Segundo dados da Organização Mundial da Saúde (OMS), em 2025, o Brasil será o sexto do mundo com o maior número de idosos. Diante desse cenário, as mudanças sociais são desafiadoras e suas implicações são profundas.

Uma criança nascida no Brasil em 2015 pode esperar viver 20 anos mais que uma criança nascida há 50 anos (OMS, 2015). Uma sociedade que envelhece demonstra seus ganhos em termos de avanços na saúde, mas apresenta o desafio de ter ações educativas que garantam, realmente, os direitos das pessoas à compreensão do envelhecimento como um processo natural ao longo do ciclo da vida.

As questões que mobilizam nossa reflexão são: Quais são as concepções da expressão tema transversal? O envelhecimento vem sendo apresentado como tema transversal no conjunto de normas e leis que se referem à Educação Básica?

Nossa intenção é apresentar os conteúdos presentes nos textos legais e normativos: Diretrizes Curriculares da Educação Básica, Parâmetros Curriculares Nacionais (PCN), Plano Nacional de Educação em Direitos Humanos, Estatuto do Idoso, Política Nacional do Idoso, Estatuto do Idoso, Plano Nacional de Educação, Deliberação CEE no 77/2008, Diretrizes Curriculares Nacionais para a EJA e Base Nacional Comum Curricular, quando da busca pelas palavras idosos, velhice e envelhecimento nesses documentos.

A importância da temática se dá mediante à urgência social e abrangência nacional e no favorecimento à compreensão da realidade atual brasileira: nossa população está envelhecendo e nós estamos vivendo mais. Num cenário como esse, 
o importante é que estudantes dos diferentes níveis e modalidades de ensino, e os educadores, possam construir significados e conferir sentido àquilo que aprendem a respeito de si mesmos e da sociedade na qual estão inseridos.

Promover a criticidade dos estudantes quanto às questões ligadas ao envelhecimento demanda uma rigorosa formação ética. Intervir e romper com uma lógica baseada na valorização da juventude implica em compreender o fato de que todos estamos envelhecendo desde o nosso nascimento. Afinal, estamos ganhando, dia a dia, mais idade.

Para alcançar nosso objetivo, o texto será dividido em duas seções. $\mathrm{Na}$ primeira, traremos as concepções da expressão tema transversal e na segunda nos dedicaremos a apresentar o resultado de nossa busca na legislação. Por fim, teceremos nossas considerações.

\section{TEMA TRANSVERSAL: CONCEPÇÕES}

A transversalidade propõe para a educação uma significativa mudança curricular. $\mathrm{O}$ termo parte da ideia de considerar uma ou mais problemáticas reais, atravessando todos os campos de conhecimento.

Os temas transversais têm natureza diferente dos conteúdos escolares. Tratam de processos que estão sendo intensamente vividos pela sociedade, pelas comunidades, pelas famílias, pelos (as) alunos (as) e educadores (as) em seu cotidiano.

Ensinar exige dos (das) educadores (as) "disponibilidade para o diálogo" (FREIRE, 1996, p. 152). Se um tema transversal dialoga com a realidade, então a "abertura ao outro como objeto da reflexão crítica deveria fazer parte da aventura docente" (FREIRE, 1996, p. 153) na perspectiva da discussão e do debate.

De acordo com Lepre (2005), no artigo intitulado Educação moral na escola: caminhos para a construção da cidadania, a discussão sobre a transversalidade na 
educação vem sendo estabelecida por diferentes autores.

Antes de nós e, provavelmente nos fornecendo modelos atuais de educação moral, autores como Cabanas (1996), Puig (1998), Buxarrais $(1990,1997)$, Martinez (1994), e Martinez e Puig (1994) chegaram à proposição da ética como tema transversal nas escolas, o que agora aparece em nossos Parâmetros Curriculares Nacionais (1998). (LEPRE, 2005, p. 2).

O livro "Temas transversais em educação: bases para uma formação integral", escrito por Busquets; Cainzos; Fernández; Leal; Moreno; e Sastre, e publicado no Brasil em 1998, é uma obra de referência para entender a concepção de transversalidade proposta pelas reformas educacionais espanholas. Dela, extraímos um trecho que justifica sua importância.

\footnotetext{
Uma das formas propostas de se influir nesse processo de transformação da sociedade, sem abrir mão dos conteúdos curriculares tradicionais, é por meio da inserção transversal, na estrutura curricular das escolas, de temas como: saúde, ética, meio ambiente, o respeito às diferenças, os direitos do consumidor, as relações capital-trabalho, a igualdade de oportunidades e a educação de sentimentos (BUSQUETS et al, 1999, p.12).
}

Os temas transversais, como a própria expressão indica, atravessam o currículo, sem se fixar numa única disciplina e sem "abrir mão dos conteúdos". A proposição destes temas é determinada segundo alguns critérios: urgência social, abrangência nacional e participação social.

Tais temas são debatidos em diferentes instituições sociais, em busca de alternativas, confrontando posicionamentos diversos tanto em relação à intervenção no âmbito social mais amplo quanto à atuação pessoal. Revelam questões urgentes que interrogam sobre a vida humana e a realidade que está sendo construída. Por esses motivos, demandam transformações macrossociais e atitudes pessoais, exigindo, portanto, ensino e aprendizagem relativos a essas duas dimensões: social e pessoal.

Os temas transversais estão presentes nos Parâmetros Curriculares Nacionais (PCN), desde 1996, e compreendem seis áreas: 1) Ética (Respeito mútuo, justiça, 
diálogo, solidariedade); 2) Orientação Sexual (Corpo: matriz da sexualidade, relações de gênero, prevenções das doenças sexualmente transmissíveis); 3) Meio Ambiente (Os ciclos da natureza, sociedade e meio ambiente, manejo e conservação ambiental); 4) Saúde (autocuidado, vida coletiva); 5) Pluralidade Cultural (Pluralidade Cultural e a vida das crianças no Brasil, constituição da pluralidade cultural no Brasil, o ser humano como agente social e produtor de cultura, Pluralidade Cultural e Cidadania); e 6) Trabalho e Consumo (Relações de trabalho; Trabalho, Consumo, Meio Ambiente e Saúde; Consumo, Meios de Comunicação de Massas, Publicidade e Vendas; Direitos Humanos e Cidadania).

Inserir no currículo discussões sobre ética, por exemplo, é reflexo da ruptura de um paradigma educacional do tipo conteudista, visto que propõe uma escola mais articulada à realidade em diálogo com questões sociais. Essa perspectiva apresentase contrastante à proposta da escola considerada "tradicional", aquela que acredita na mera transmissão de conteúdo, ou seja, baseada numa "Educação bancária" (Freire, 1996), e segue na busca de uma escola permeada por uma ética humanizadora.

Para Freire (1996), "Ensinar exige compreender que a educação é uma forma de intervenção no mundo" (p.8). Ler o mundo que envelhece e nele intervir exige dos educadores uma tomada de posição a favor, por exemplo, da luta contra qualquer forma de discriminação contra pessoas idosas. A esperança de um futuro melhor para - Brasil passa pelo entendimento de que a legislação deve ser respeitada e, principalmente, colocada em prática.

O desafio que se coloca é que conhecendo, compreendendo e respeitando as bases legais seria uma contradição não as defender nem as comunicar e colocá-las em prática. $O$ envelhecimento populacional brasileiro é um fato social que, por sua abrangência nacional, demanda urgentemente a participação de todos, profissionais da educação ou não. Justifica-se, assim, a busca empreendida por nós em nosso estudo cujos resultados apresentaremos na próxima seção desse artigo. 


\section{O ENVELHECIMENTO COMO TEMA TRANSVERSAL: BASES LEGAIS}

A educação Básica considera os princípios da equidade e da valorização da diversidade, os direitos humanos, a gestão democrática do ensino público, a garantia de padrão de qualidade, a acessibilidade, a igualdade de condições para o acesso e permanência do educando na escola (BRASIL, 2013). Entendemos a educação como "processo permanente" (FREIRE, 1996, p. 64) que consiste na "força criadora do aprender" (FREIRE, 1996, p. 28) ao longo da vida.

A Educação Básica se compõe pela educação infantil, pelo ensino fundamental (I e II) e pelo ensino médio e pretende ser o caminho para assegurar a todos os brasileiros a formação comum indispensável para o exercício da cidadania e fornecerIhes os meios para progredir no trabalho e em estudos posteriores. Os documentos que descrevem as bases para a Educação Básica são a Lei ํㅜ 9.394, de 1996, que estabelece as Diretrizes e Bases da Educação Nacional (LDB), as Diretrizes Curriculares Nacionais para a Educação Básica, de 2013, e o Plano Nacional de Educação, aprovado pelo Congresso Nacional em 26 de junho de 2014.

Na LDB, em sua versão atualizada em Janeiro de 2019, nenhum dos termos por nós buscados aparece no texto do documento. As Diretrizes Curriculares da Educação Básica (DCEB) trazem que "Outras leis específicas, a latere da LDB, determinam que sejam incluídos componentes não disciplinares, como as questões relativas ao meio ambiente, à condição e direito do idoso e ao trânsito." (BRASIL, 2013, p.33).

Nas DCEB, encontramos quatro ocorrências do termo envelhecimento, quando o texto trata de organização curricular: "Tratados transversal e integradamente, permeando todo o currículo, no âmbito dos demais componentes curriculares: o processo de envelhecimento, o respeito e a valorização do idoso, de forma a eliminar o preconceito e a produzir conhecimentos sobre a matéria (Lei no 10.741/2003: Estatuto do Idoso)." (BRASIL, 2013, p. 196). A palavra velhice não aparece nas Diretrizes.

Uma escola livre de preconceitos demanda ações educativas em direitos 
humanos. De acordo com o Plano Nacional de Educação em Direitos Humanos (PNEDH), a Educação em Direitos Humanos deve estruturar-se na diversidade, garantindo a equidade geracional (BRASIL, 2007). Em sua introdução, o PNEDH destaca diversos atores políticos que devem ter seus direitos reconhecidos. $O$ texto traz que "a adoção do princípio de empoderamento em benefício de categorias historicamente vulneráveis (mulheres, negros(as), povos indígenas, idosos(as)." (BRASIL, 2007, pp. 21-22).

Na seção denominada Ações Programáticas, dividida em vinte e seis itens, encontramos a palavra idoso na décima ação, descrita como

10. fomentar ações educativas que estimulem e incentivem o envolvimento de profissionais dos sistemas com questões de diversidade e exclusão social, tais como: luta antimanicomial, combate ao trabalho escravo e ao trabalho infantil, defesa de direitos de grupos sociais discriminados, como mulheres, povos indígenas, gays, lésbicas, transgêneros, transexuais e bissexuais (GLTTB), negros(as), pessoas com deficiência, idosos(as), adolescentes em conflito com a lei, ciganos, refugiados, asilados, entre outros (BRASIL, 2007, p. 51).

Uma educação que se estrutura na diversidade e na "defesa de direitos de grupos sociais discriminados" dá valor à diferença etária, considerando-a como parte importante de uma convivência respeitosa e solidária. Garantir a equidade geracional implica em reconhecer, igualmente, o direito de cada uma das pessoas de diferentes idades.

Se pensarmos que uma geração será constituída por nossos filhos, a seguinte por nossos netos, mais adiante nossos bisnetos e assim sucessivamente, cada uma delas legará o futuro aos seus descendentes imediatos. O respeito e a valorização da pessoa idosa, de forma a eliminar qualquer tipo de preconceito e a produzir conhecimentos sobre o tema, precisa ser nosso legado às gerações seguintes e o que se espera que tenha continuidade.

As leis existem para regular o comportamento dos indivíduos dentro de uma sociedade estabelecendo seus direitos e deveres. Representam conquistas sociais, 
porque não são dadas. Porém, o fato de uma norma jurídica existir não é suficiente para afirmar que ela é seguida.

O Estatuto do Idoso, que entrou em vigor em 1ํ de outubro de 2003, através da lei 10.741/03, em sua versão atualizada em Junho de 2017, traz no capítulo cinco os temas Educação, Cultura, Esporte e Lazer. No terceiro artigo do título I, temos que

Art. 3o É obrigação da família, da comunidade, da sociedade e do Poder Público assegurar ao idoso, com absoluta prioridade, a efetivação do direito à vida, à saúde, à alimentação, à educação, à cultura, ao esporte, ao lazer, ao trabalho, à cidadania, à liberdade, à dignidade, ao respeito e à convivência familiar e comunitária (BRASIL, 2017, p. 8).

Os direitos à educação e ao respeito são reforçados no capítulo V do Estatuto. O artigo vinte e um destaca que "O Poder Público criará oportunidades de acesso do idoso à educação, adequando currículos, metodologias e material didático aos programas educacionais a ele destinados." (BRASIL, 2017, p. 14). E no artigo vinte e dois, o texto traz a indicação de que "Nos currículos mínimos dos diversos níveis de ensino formal serão inseridos conteúdos voltados ao processo de envelhecimento, ao respeito e à valorização do idoso, de forma a eliminar o preconceito e a produzir conhecimentos sobre a matéria." (BRASIL, 2017, p. 14).

O Plano Nacional de Educação determina diretrizes, metas e estratégias estabelecidas em 2014 e válidas até 2024. A ideia principal é garantir o direito à educação básica com qualidade.

O termo idoso aparece uma única vez, ao longo do documento, na meta nove, que trata sobre a educação de Jovens e Adultos. O texto indica que

As ações planejadas devem ter como objetivo a superação do analfabetismo entre jovens com 15 anos ou mais, adultos e idosos, concebendo a educação como direito, e a oferta pública da alfabetização como porta de entrada para a educação e a escolarização das pessoas ao longo de toda a vida (BRASIL, 2014, p. 35). 
$\mathrm{Na}$ busca da efetividade dos princípios constitucionais, foi implementada no Brasil a Lei no 8842, de 4 de janeiro de 1994 (Brasil, 1994), que dispõe sobre a Política Nacional do Idoso (PNI). A PNI surge no cenário brasileiro como a explicitação das políticas que o Estado estabelece em relação às pessoas idosas.

A estrutura da PNI se apresenta dividida em quatro capítulos: i) Da finalidade; ii) Dos princípios e das Diretrizes; iii) Da organização; e iv) Das ações governamentais (arts. 10 a 22), que trata da implementação da PNI nas áreas de promoção e assistência social, saúde, educação, trabalho e previdência social, habitação e urbanismo, justiça, cultura, esporte e lazer. No que tange às questões ligadas à educação, seis intenções são destacadas no documento.

Duas delas, relacionadas principalmente à educação básica, serão apresentadas e discutidas: 1) adequar currículos, metodologias e material didático aos programas educacionais destinados ao idoso; 2 ) inserir nos currículos mínimos, nos diversos níveis do ensino formal, conteúdos voltados para o processo de envelhecimento, de forma a eliminar preconceitos e a produzir conhecimentos sobre 0 assunto.

No que se refere à primeira intenção, sabe-se que no Brasil, a educação permanente no contexto do envelhecimento encontra-se nos espaços de aprendizagem destinados à educação formal e não formal. A educação de jovens $\mathrm{e}$ adultos (EJA), modalidade de ensino do âmbito da educação formal, voltada às pessoas não alfabetizadas ou com pouca escolarização, atende ao idoso, mas não pode ser considerada como um programa educacional destinado exclusivamente a este segmento.

Nas Diretrizes Curriculares Nacionais para a EJA - Parecer da Câmara de Educação Básica CEB 11/2000 -, o idoso é citado.

A barreira posta pela falta de alcance à leitura e à escrita prejudica sobremaneira a qualidade de vida de jovens e de adultos, estes últimos incluindo também os idosos, exatamente no momento em que o acesso ou não ao saber e aos meios de obtê-lo representam uma divisão cada vez mais 
significativa entre as pessoas. No século que se avizinha, e que está sendo chamado de "o século do conhecimento", mais e mais saberes aliados a competências tornar-se-ão indispensáveis para a vida cidadã e para o mundo do trabalho. Adulto é o ente humano já inteiramente crescido. O estado de adulto (adultícia) inclui o idoso. Este parecer compreende os idosos como uma faixa etária sob a noção de adulto (BRASIL, 2000, p. 8).

Apesar da inclusão do termo idoso no Parecer que trata da EJA, percebe-se que suas necessidades educacionais não serão contempladas ao caracterizá-lo como adulto. Os idosos que frequentam a EJA representam cerca de 3\% das matrículas do segmento no país, segundo o Censo Escolar 2012, e fazem parte de uma parcela da população que não teve oportunidade de frequentar a sala de aula na "faixa etária apropriada". Segundo o Instituto Brasileiro de Geografia e Estatística (IBGE), em 2012, mais de 10 milhões de brasileiros com mais de 60 anos não sabem ler ou escrever.

O perfil sociodemográfico dos idosos brasileiros, elaborado pela Fundação Perseu Abramo e pelo Serviço Social do Comércio (SESC) em 2007, detalha melhor o cenário. Segundo o estudo, o analfabetismo funcional atinge $49 \%$ das pessoas acima de 60 anos. Entre elas, 18\% não receberam educação formal, e 89\% não concluíram o ensino fundamental.

Todaro e Lima (2010) constataram, em uma pesquisa sobre a EJA, uma inadequação da organização dos espaços escolares, do uso do tempo e dos materiais didáticos, que infantilizam os aprendizes. Além disso, os preconceitos dos educadores em relação a esses alunos são uma constante que, na visão dessas autoras, precisam ser analisados e levados em consideração quando da proposição de alternativas metodológicas. Quanto aos jovens, adultos e idosos, sabe-se que são, basicamente, "não crianças" e, por este motivo, não podem ser vítimas de métodos e materiais infantilizados.

Pode-se afirmar, portanto, que a intenção da Política Nacional do Idoso a respeito de currículos, metodologias, material didático e programas educacionais destinados ao idoso é um dos muitos desafios enfrentados por professores (as), coordenadores (as) de programas e pesquisadores (as) com formação em pedagogia 


\section{Envelhecimento como tema transversal na educação básica}

Mônica de Ávila Todaro e Meire Cachioni

e/ou gerontologia, que buscam possibilidades para lidar com este cenário de envelhecimento, também presente na Educação de Jovens e Adultos.

Ainda sobre a PNI, encontramos uma segunda intenção: "inserir nos currículos mínimos, nos diversos níveis do ensino formal, conteúdos voltados para o processo de envelhecimento, de forma a eliminar preconceitos e a produzir conhecimentos sobre o assunto". Desde a primeira Conferência Nacional dos Direitos da Pessoa Idosa, em 2006, no eixo da educação, foi deliberada a inserção do envelhecimento como tema transversal em todos os níveis de ensino formal. Essa intenção também se encontra redigida no artigo vinte e dois do Estatuto do Idoso.

Mesmo que esteja presente nos dois textos, surge um questionamento: Como inserir tal tema na Educação Básica, se conteúdos ou disciplinas ligadas à Gerontologia não estão presentes nos cursos de licenciatura?

Os Parâmetros Curriculares Nacionais (PCN), ainda utilizados como referência nas matrizes curriculares dos cursos de licenciatura, foram organizados posteriormente à Política Nacional do Idoso. Mesmo assim, não apresentam o envelhecimento como um dos temas transversais. Há apenas uma indicação referente ao processo de envelhecimento e à velhice, no PCN do Ensino Fundamental de Ciências Naturais, quando se trata do desenvolvimento humano, sendo, portanto, considerado mais um conteúdo fixo do que um tema transversal.

No contexto estadual, São Paulo tem um ato administrativo normativo interessante. A Deliberação CEE no 77/2008, do Conselho Estadual de Educação, estabelece orientações para a organização dos componentes curriculares do ensino fundamental II e no ensino médio do sistema de ensino. O 16º componente curricular obrigatório refere-se aos conhecimentos sobre o processo de envelhecimento. Há a indicação de que será a equipe pedagógica da instituição ou da rede de ensino que decidirá como serão trabalhados os componentes curriculares e sua distribuição na programação de ensino, considerando a matriz curricular como representação da proposta pedagógica da escola.

A partir da análise desse documento, percebe-se que a iniciativa é muito 
importante, no entanto, de acordo com as informações concedidas pelos membros do Centro de Estudos e Normas Pedagógicas (CENP), Albuquerque e Cachioni (2013) constataram que não houve uma efetiva inserção da temática envelhecimento na rede de ensino paulista. As escolas possuem autonomia para inserir o tema nos seus currículos, mas a ideia ainda não foi, realmente, incorporada. Para as autoras, faz-se necessária uma capacitação da equipe pedagógica, entendida como diretor, supervisor, coordenador e professores, a fim de que a inserção do tema seja efetiva e coerente com a produção de conhecimentos científicos da área.

A Base Nacional Comum Curricular (BNCC) é um documento de caráter normativo aprovado em 2017. Ele define o conjunto de aprendizagens essenciais que todos os alunos devem desenvolver ao longo das etapas e modalidades da Educação Básica, em conformidade com o Plano Nacional de Educação (PNE).

Numa busca no documento pelas palavras velhice, nada foi encontrado. Porém, quando inserimos os termos envelhecimento e idoso, destacamos o trecho que se refere aos temas: processo de envelhecimento, respeito e valorização do idoso e que faz referência ao Estatuto do Idoso (Lei no 10.741/2003). De acordo com o texto, temos que

\footnotetext{
Por fim, cabe aos sistemas e redes de ensino, assim como às escolas, em suas respectivas esferas de autonomia e competência, incorporar aos currículos e às propostas pedagógicas a abordagem de temas contemporâneos que afetam a vida humana em escala local, regional e global, preferencialmente de forma transversal e integradora (BRASIL, 2017, p. 19).
}

Se quisermos, realmente, uma sociedade que se destaca pelo respeito mútuo entre pessoas de diferentes idades, faz-se necessário entender que "a educação pode desempenhar um papel central em qualquer projeto de mudança em relação à velhice" (Cachioni \& Todaro, 2016). Não basta, portanto, que tenhamos parâmetros, diretrizes e leis sobre a temática. É imprescindível que o tema realmente se incorpore ao currículo, atravessando-o e afetando estudantes de diferentes níveis de escolarização. 
A pesquisa de Todaro (2008) indicou a necessidade de inserir o envelhecimento como tema transversal no Ensino Fundamental I. Trouxe, em seu bojo, sugestões para colocar tal ideia em ação, o que a autora chamou de uma possível "Ação educativa gerontológica" que, numa perspectiva de educação problematizadora (Freire, 1996), leva à mudança de atitudes. Na certeza de que "o amanhã não é algo pré-dado, mas um desafio, um problema." (FREIRE, 1996, p.84), precisamos construir uma sociedade menos preconceituosa e mais solidária.

Para tanto, merecem nossa atenção o contexto brasileiro de envelhecimento populacional e as bases legais que sustentam a defesa de práticas educativas ligadas ao envelhecimento como tema transversal. $O$ envelhecimento, a velhice e os idosos podem ser mais do que apenas temas que aparecem nas escolas como efeméride, como por exemplo, a comemoração do "Dia dos avós". A potência de uma educação para o envelhecimento atravessa educadores, pesquisadores e comunidade, afetando nossas sensibilidades. 


\section{CONSIDERAÇÕES FINAIS}

À guisa de conclusão, retomamos as questões que foram apresentadas inicialmente nesse texto: Qual a concepção de tema transversal? O envelhecimento vem sendo apresentado como tema transversal na legislação que se refere à Educação? Arriscamos afirmar que o envelhecimento vem sendo, sim, apresentado como tema transversal na legislação que se refere à Educação Básica, em consonância com as concepções teóricas da expressão.

Embora o envelhecimento apareça nos dispositivos legais, num contexto em que as pessoas idosas estão ganhando maior visibilidade, nos perguntamos se a inserção do tema tem sido feita nos diferentes níveis de escolarização. Tal questão revela nossa preocupação com uma lacuna a ser preenchida desde a formação de professores (as) tanto pelos cursos de licenciatura, revendo suas matrizes curriculares e aliando-as às bases legais atuais, quanto na formação continuada daqueles que já são trabalhadores da educação.

Os possíveis caminhos para que a temática atravesse os currículos e seja incorporada nas escolas podem ser apontados por pesquisadores (as) e profissionais das áreas de Educação e de Gerontologia. Porém, demandam uma atuação junto às redes e aos sistemas de ensino, por sua efetivação.

Nada mais urgente do que compreender a realidade de um país que envelhece populacionalmente. Compreender a heterogeneidade da velhice, diante da desigualdade econômica e social, desafia nosso modo de participar da sociedade.

A educação para o envelhecimento, via tema transversal, não é viabilizada por decreto, resolução, portaria ou similar. Tampouco se efetiva somente por meio de parâmetros ou diretrizes curriculares.

Uma outra educação possível, a das sensibilidades, é conquista da sociedade brasileira que envelhece e precisa ser manifesta pelo diálogo entre idosos, educadores e pesquisadores. Estabelecer um diálogo aberto entre tais atores é lutar pela coerência entre os direitos que estão no papel e sua verdadeira efetivação. 
Temas transversais, que incluam questões éticas que possibilitem a compreensão e a crítica da realidade, podem oferecer aos estudantes a oportunidade de refletir e mudar suas atitudes, numa dimensão pessoal. E podem, também, disponibilizar saberes necessários à prática de construção de uma sociedade na qual é possível "Viver a abertura respeitosa aos outros." (FREIRE, 1996, p. 153). Crianças, jovens e adultos serão idosos e, portanto, outros que todos nós já estamos gestando ao longo do ciclo da vida, envelhecendo. 


\section{REFERÊNCIAS}

ALBUQUERQUE, M. S.; CACHIONI, M. Pensando a gerontologia no ensino fundamental. Revista Kairós Gerontologia, v. 16, n. 5, p. 141-163, set. 2013.

BRASIL. Lei no 8.842, de janeiro de 1994. Dispõe sobre a política nacional do idoso, cria o Conselho Nacional do Idoso e dá outras providências. Brasília: Diário Oficial da União, 1994.

BRASIL. Parâmetros Curriculares Nacionais para o Ensino Fundamental. Brasília, MEC/SEF, 1997.

BRASIL. Constituição da República Federativa do Brasil. Brasília: Senado Federal, 1998.

BRASIL. Diretrizes curriculares nacionais para a educação de jovens e adultos. Brasília: MEC, 2000.

BRASIL. Plano Nacional de Educação em Direitos Humanos. Brasília: Secretaria Especial dos Direitos Humanos, Ministério da Educação, Ministério da Justiça, UNESCO, 2007.

BRASIL. Diretrizes Curriculares Nacionais da Educação Básica. Brasília, 2013. Disponível em http://portal.mec.gov.br/secretaria-de-educacao-básica. Acesso em 04 Set. 2020.

BRASIL. Plano Nacional de Educação. Brasília: Câmara dos Deputados, 2014.

BRASIL. Base Nacional Comum Curricular. Brasília: MEC/Secretaria de Educação Básica, 2017.

BUSQUETS, M. D.; Cainzos, M.; Fernández, T.; Leal, A.; Moreno, M.; e Sastre, G. Temas transversais em educação: bases para uma formação integral. São Paulo: Ática, 1999.

CACHIONI, M.; TODARO, M. A. Política Nacional do Idoso: reflexão acerca das intenções direcionadas à educação formal. In.: Alcântara, A.; Camarano, A. A.; Giacomin, K. Política Nacional do Idoso: velhas e novas questões. Brasília: IPEA, 2016.

FREIRE, P. Pedagogia da autonomia. São Paulo: Paz e Terra, 1996.

LEPRE, R. M. Educação moral na escola: caminhos para a construção da cidadania. Colloquium Humanarum., 3(1), 01-14. Disponível em http://journal.unoeste.br/index.php/ch/article/view/207 Acesso em 02 Set. 2020.

NERI, A. L. (Org.). Idosos no Brasil: vivências, desafios e expectativas na terceira idade. São Paulo: Fundação Perseu Abramo/Editora SESC, 2007.

OMS. Relatório Mundial de Envelhecimento e Saúde [Internet]. Geneva: OMS, 2015. Disponível em: http://apps.who.int/ iris/bitstream/10665/186463/1/9789240694811_eng. pdf?ua=1. Acesso em: 2 Set.2020.

TODARO, M. A. Desenvolvimento e avaliação de um programa de leitura visando a mudança de atitudes de crianças em relação a idosos. 2008. Tese (Doutorado) - Universidade Estadual de Campinas, Campinas, 2008.

TODARO, M. A.; LIMA, M. A. F. Alfabetizar sem infantilizar: um desafio para a educação de jovens, adultos e idosos. In: CONGRESSO INTERNACIONAL DA CÁTEDRA UNESCO DE EDUCAÇ̃̃O DE JOVENS E ADULTOS, 1., 2010. Anais. João Pessoa: UFPB, 2010. Disponível em: <http://www.catedraunescoeja.org/GT01/COM/COM009.pdf>. Acesso em: 1 Set. 2020. 
